\title{
Publisher Correction: Bistable and photoswitchable states of matter
}

\author{
Brady T. Worrell', Matthew K. McBride ${ }^{1}$, Gayla B. Lyon ${ }^{1,7}$, Lewis M. Cox ${ }^{1,2,3}$, Chen Wang ${ }^{1,7}$, \\ Sudheendran Mavila1, Chern-Hooi Lim ${ }^{1,8}$, Hannah M. Coley ${ }^{4}$, Charles B. Musgrave ${ }^{1}$, Yifu Ding ${ }^{3,4} \&$ \\ Christopher N. Bowman (i) 1,4,5,6
}

Correction to: Nature Communications, https://doi.org/10.1038/s41467-018-05300-7, published online: 18 July 2018

The original version of this Article contained errors in Fig. 3. In Fig. 3a, the word 'fluid' in grey was incorrectly given as 'solid' in green, below that, 'solid' in green was previously 'fluid' in grey. Also, the label on the arrow incorrectly read 'TMG (1 mol\%) HABI-Cl (3 mol \%) $455 \mathrm{~nm}, 1 \mathrm{~min}$ '; the correct version reads 'TMG (1 mol\%) HABI-O-n-oct (4 mol\%) $455 \mathrm{~nm}, 4$ min'. In the accompanying legend, the word 'photobase' was originally incorrectly given as 'photoacid'. Additionally, in Fig. 3b, the label on the central image was 'As is: solid', rather than the correct 'As is: fluid'. This has been corrected in both the PDF and HTML versions of the Article.

Published online: 07 August 2018 \begin{abstract}
and indicate if changes were made. The images or other third party material in this article are included in the article's Creative Commons license, unless indicated otherwise in a credit line to the material. If material is not included in the article's Creative Commons license and your intended use is not permitted by statutory regulation or exceeds the permitted use,
\end{abstract}

(c) Open Access This article is licensed under a Creative Commons Attribution 4.0 International License, which permits use, sharing, adaptation, distribution and you will need to obtain permission directly from the copyright holder. To view a copy of this license, visit http://creativecommons.org/licenses/by/4.0/.

(C) The Author(s) 2018

\footnotetext{
${ }^{1}$ Department of Chemical and Biological Engineering, University of Colorado, Boulder, CO 80309, USA. ${ }^{2}$ Applied Chemicals and Materials Division, National Institute of Standards and Technology, Boulder, CO 80305, USA. ${ }^{3}$ Department of Mechanical Engineering, University of Colorado, Boulder, CO 80309, USA. ${ }^{4}$ Material Science and Engineering Program, University of Colorado, Boulder, CO 80309, USA. ${ }^{5}$ BioFrontiers Institute, University of Colorado, Boulder, CO 80309, USA. ${ }^{6}$ Department of Restorative Dentistry, University of Colorado, Anschutz Medical Campus, Aurora, CO 80045, USA. ${ }^{7}$ Present address: Formlabs Inc, 35 Medford St. \#201, Somerville, MA 02143, USA. ${ }^{8}$ Present address: Department of Chemistry, Colorado State University, Fort Collins, CO 80523, USA. The original article can be found online at https://doi.org/10.1038/s41467-018-05300-7. Correspondence and requests for materials should be addressed to C.N.B. (email: Christopher.Bowman@colorado.edu)
} 